\section{PROFESSIONAL PAPER}

doi: 10.5455/medarh.2015.69.417-420

Med Arh. 2015 Dec; 69(6): 417-420

Received: August 25th 2015 | Accepted: October 25th

2015

(C) 2015 Lana Ayesh Habahbeh, Mansour al Hiary, Samar F. Al Zaben, Asim AlMomani, Rame Khasawneh, Mervat abu Mallouh, Hayab Farahat

This is an Open Access article distributed under the terms of the Creative Commons Attribution Non-Commercial License (http://creativecommons.org/licenses/ by-nc/4.0/) which permits unrestricted non-commercial use, distribution, and reproduction in any medium, provided the original work is properly cited.

\title{
Genetic Profile of Patients
}

with Familial Mediterranean Fever (FMF): Single Center Experience at King Hussein Medical Center (KHMC)

Lana Ayesh Habahbeh, Mansour al Hiary, Samar F. Al Zaben, Asim Al-Momani, Rame Khasawneh, Mervat abu Mallouh, Hayab Farahat

Department of Pathology, King Hussein Medical Center, Amman, Jordan

Corresponding author: Rame, Khasawneh, MD. E-mail: dr.r.khasawneh@gmail.com

\section{ABSTRACT}

Objective: To describe the spectrum of genetic mutations in patients with clinical diagnosis of Familial Mediterranean Fever. Method: This is a retrospective study of 3359 sera samples for patient with clinical diagnosis of FMF, over a period of 6 years. The samples were tested for 12 mutations of the MEFV gene by PCR\& hybridization of the PCR product with Probes immobilized as an array of panel lines. Results: A total of 1868 (55.6\%) samples were found negative, and one or more mutations were detected in 1491 (44.4\%) distributed along the mutations. Of the positive results, the Frequency of the mutations was as follows, the M694V was the most common mutation 30\%, followed by E 148Q $21.5 \%$, V 726 A 20\%, M6801 G/C $9 \%$, M6941 8.3\%, P369s 3.7\%, A744S 3.1\% and 4.2\% among the 4 remaining mutations. Conclusion: Frequency of common mutations in our study show similar results in comparisons with Mediterranean countries like Egypt, Turkey, and Syria with the most common mutation in our study being M694V followed by E148 Q.

Key words: FMF, genotype, King Hussein Medical Center.

\section{INTRODUCTION}

Familial Mediterranean Fever (FMF) is an autosomal recessive inherited auto inflammatory disorder (1), most commonly seen in populations of Mediterranean ancestry, like Arabs, Turks, Jews and Armenians $(2,3,4)$. This disease is characterized by recurrent episodes of fever 38-40c (5), arthritis and serositis (6). The FMF gene, MEFV was identified by positional cloning in 1997 (French FMF Consortium 1997; International FMF Consortium 1997) (7), it's located on chromosome 16p 13.3 (8), the MEFV gene has a 2,346 bp coding sequence, which spans 10 exons (9) with exon 10 showing the more frequent mutations (10) at two hot spots, one at codon 694 and the other one at codon 680 (2) followed by exon 2, 3, 5 and 9 (3). MFEV gene product is a 781 aa protein known as pyrin or marenostrin (8), that has a regulatory effect on inflammation, and so abnormality in its production would produce an inappropriate inflammatory reaction (9) as seen in FMF manifested as recurrent attacks of fever, arthritis ,pleuritis and sterile peritonitis (11). Amyloidosis is the most sever complication of the disease $(4,12)$, specially renal amyloidosis leading to an end stage renal disease (5), daily colchicines is the main treatment (13) showed to lower the severity and frequency of attacks and the chance of developing amyloidosis (1).

The most frequent mutations among Arab, Turks, Jews and Iranians are M694V, E148Q, M680I, M694V and V726A (3, 10, 12-15). The order and percentage however is different among each population from the above mentioned ones, and the mutations differ in penertrance and correlation with severity of clinical symptoms, with E148Q having the least penertrance and recog- 
nized to have a milder clinical course $(2,9)$, while M694V recognized as the most severe and with increased risk of amyloidosis $(4,14,16)$.

This study aims to identify the spectrum of FMF mutations is patients with clinical picture of FMF at KHMC.

\section{METHOD}

This retrospective study was conducted on a 3359 sera samples, for patients with clinical diagnosis of FMF over a 6 years period $1 / 1 / 2006-1 / 11 / 2013$, the samples were tested for 12 mutations of MEFV gene, using the FMF STRIP ASSAY TM. VIENNA LAB DIAGNOSTICS $\mathrm{GmbH}$. DNA was extracted from whole blood, amplified by PCR, then by hybridization of the amplified product to a test strip that contains allele specific oligonucleotide probes immobilized as an array of panel lines, then the bound biotinylated sequences are detected using streptavidine-alkaline phosphatase and color substrate. The assay covers 12 mutations in MEFV gene which are: E148Q, P369S, F479L, M680I (G/C), 1692 DEL, M694V, M694I, and M680I (G/A), K695R, V726A, A744S, R761H.

\section{RESULTS}

A total of 1868 (55.6\%) samples were found negative, and one or more mutations were detected in 1491 (44.4\%) distributed along 57 set of mutations, with heterozygous mutation detected in $872(58.5 \%)$ patients, compound heterozygous mutations detected in 383 (25.6\%), homozygous mutation detected in 226 (15.2\%), and10 (0.7 \%) were rare complex mutations. The Frequency of the mutations was as follows, the M694V was the most common mutation $30 \%$, followed by E 148Q 21.5\%, V 726 A 20\%, M6801 G/C 9\%, M6941 8.3 \%, P369s 3.7 \%, A744S $3.1 \%$

\begin{tabular}{ll}
\hline The Mutation Genotype & Number of patients \\
\hline A744S/ & 49 \\
\hline E148Q/ M694I & 15 \\
\hline E148Q/ M694V & 31 \\
\hline E148Q/ P369S & 20 \\
\hline E148Q /V726A & 30 \\
\hline E148Q / & 283 \\
\hline E148Q / E148Q & 27 \\
\hline M6801 (G/C) / M6801 (G/C) & 40 \\
\hline M6801 (G/C) , V726A & 25 \\
\hline M680I (G/C) , M694V & 17 \\
\hline M680I (G/C) / & 43 \\
\hline M694 I / M694 I & 28 \\
\hline M694I ,/V726A & 33 \\
\hline M694I / & 43 \\
\hline M694V / & 176 \\
\hline M694V/ M694 V & 136 \\
\hline M694V / M694I & 19 \\
\hline M 694V/ V726A & 113 \\
\hline V726A / & 154 \\
\hline V726A / V726A & 24 \\
\hline P369s / & 53 \\
\hline Other 36 mutation which each has less & 133 \\
than 15 patients & \\
\hline
\end{tabular}

Table 1. The mutations and their frequencies. and $4.2 \%$ among the 4 remaining mutations. Table 1 and Figure 1 show the mutations and their frequencies.

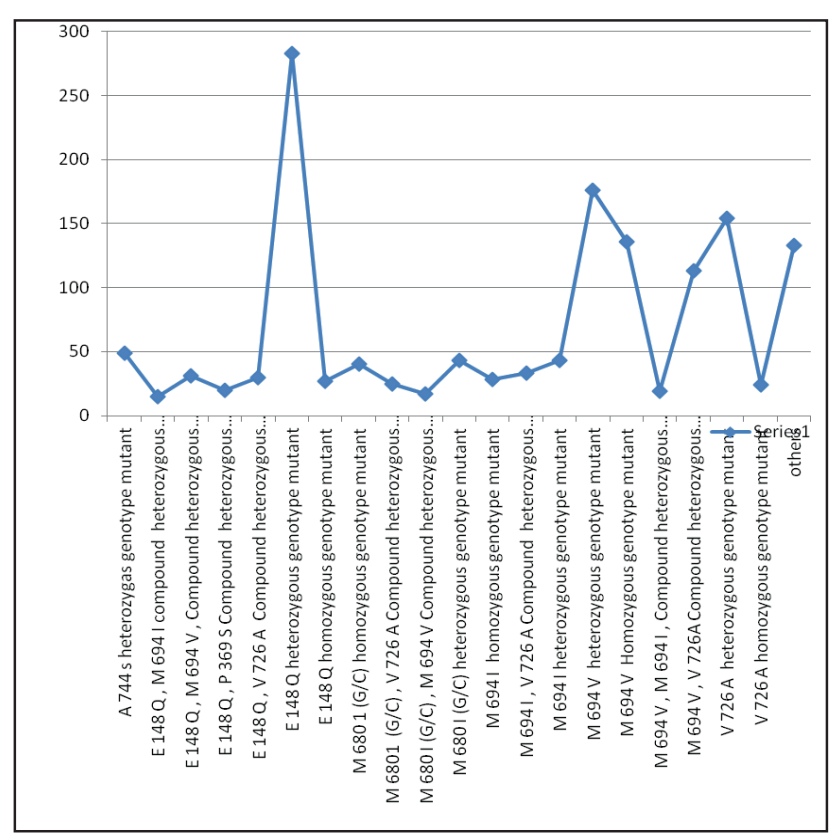

Figure 1. The mutations and their frequencies

\section{DISCUSSION}

Although clinical symptoms and the course of the illness are still the cornerstone of diagnosing FMF, molecular confirmation can help make the diagnosis earlier in suspected cases (3). In our study the heterozygous were the most common mutations with $(58.5 \%)$, followed by compound heterozygous with (25.6\%), homozygous mutation detected in $226(15.2 \%)$ patient, and $(0.7 \%)$ were rare complex mutations. It is in contrast to previous study done in Jordan in 2006 were the compound heterozygous was the most common (3) but with consistent with a study done in Turkey very recently in 2014 by Oztuzcu S where heterozygous mutations were found to be the most common in (62.3\%) (17) and similar to findings by Solak et al where heterozygous mutations were found in $(51 \%)$, compound heterozygous in $(25.8 \%)$, homozygous in $(22.2 \%)$ and (1\%) complex alleles (18). The most common mutations in our study were as follows the M694V was the most common mutation 30\%, followed by E 148Q 21.5\%, V 726 A 20\%, M6801 G/C 9\%, M6941 $8.3 \%$, P369s $3.7 \%$, A744S 3.1\% and 4.2\% among the 4 remaining mutations, as seen in Figure 2.

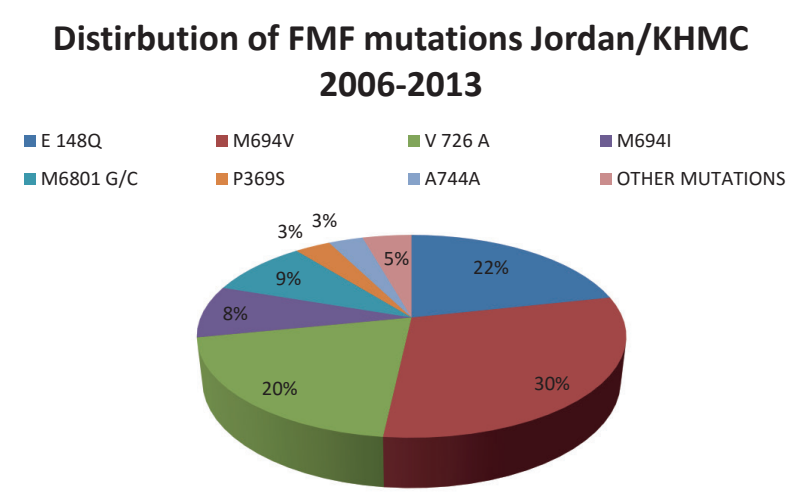

Figure 2. Distribution of FMF mutations in Jordan /KHMC 2006-2013 


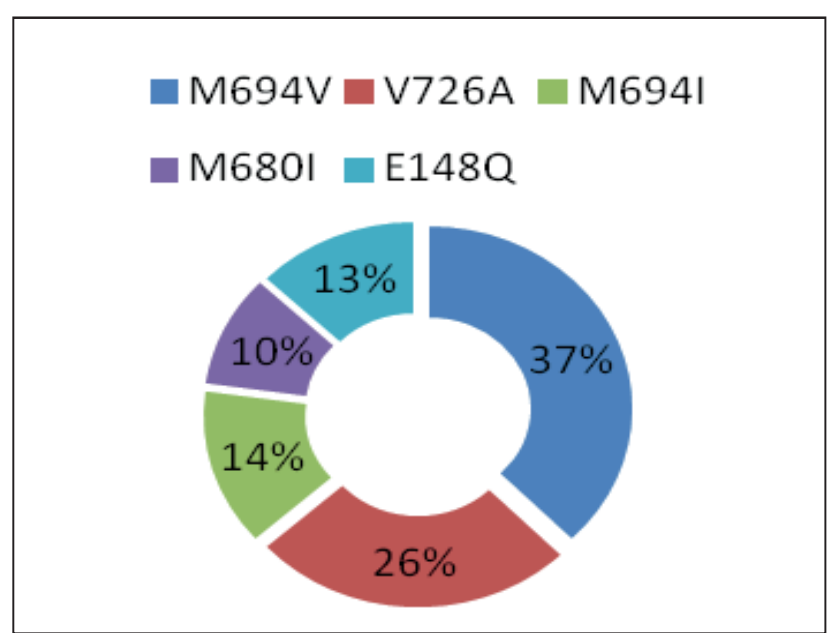

Figure 3. Gene mutation in Arabs

The first 5 mutations are among the most common mutations which are M694V, E148Q, M680I, M694V and V726A $(3,10,12,14,15)$ and A744S seems to be specific to Arab population (19) which might explain why in Jordan it has such a percentage.

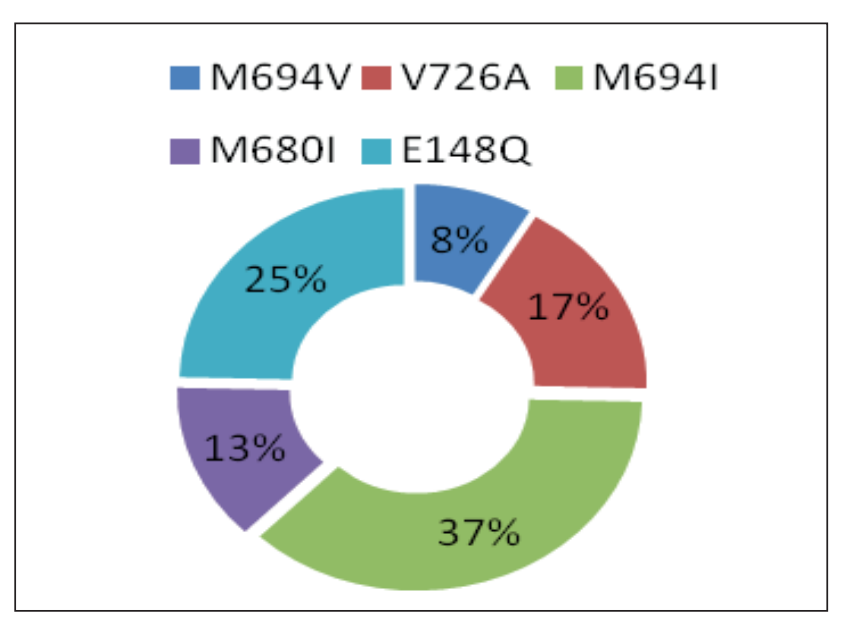

Figure 4. MEFV gene mutations in Egyptian patients

A study conducted in Jordan by HA. Majeed et al found the most common mutations in Arabs to be M694V, as shown in Figure 3 (20), another study done by el Gezery D shown the mutations in Egyption patients with FMF to be M694I, as shown in Figure 4 (21), Medlej-Hashim et al findings are showed in Figure 5 (22), Matti et al studied the Syrian population for FMF mutations and findings are shown in Figure 6 (23), mutations in Iranian Azeri Turks were shown by Bonyadi to be as in Figure 7 (24).

The mutations among different populations of high prevalence of FMF including the Jordanian patients on which this study was conducted, seem to be similar, but they differ in the order and percentage. In our study there's an increases in percentage of E148Q as compared to previous studies done in Jordan where M694V was the most common followed by V726A (21) and in consistence to other population were again M694V was the most common $(20,22,23,24)$. A possible explanation for the above mentioned results is that the higher frequency of M694V could be due to the fact that this mutation is associated with more severe symptoms that make the

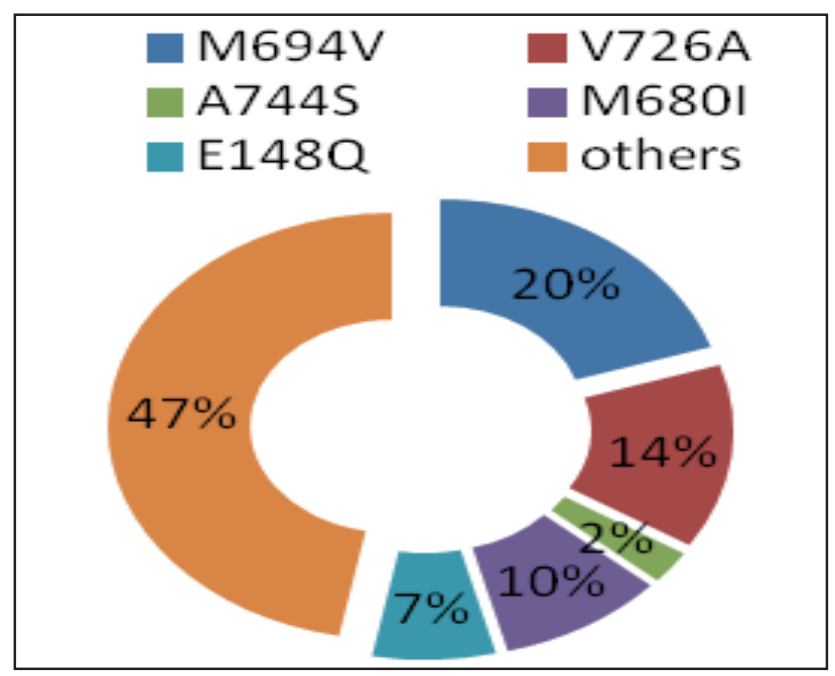

Figure 5. Genetic mutations in Jordanian FMF patients

patient seek medical help, and the physician to have a high index of suspicion of FMF, which leads to sending the patient to make molecular confirmation, while the E148Q mutation has low penertrance (15), and milder clinical course which may not bring the patient to the physician, or if they come, their mild symptoms may not be attributed to FMF. So with that low suspicion index they will not be sent for molecular confirmation, and so a lot of cases might be missed, as the suspicion index increases the detection of this mutation does too. In time and with keeping a higher index of suspicion of FMF our belief is that the E148Q frequency will be on a rise.

Heterozygosity regardless of type of mutations represents the most common finding in our cases, despite the fact that in an autosomal recessive pattern of inheritance, homozygosity should prevail. Different explanations could shed light on such a contradiction in FMF; the kit used for molecular identification of MEFV gene

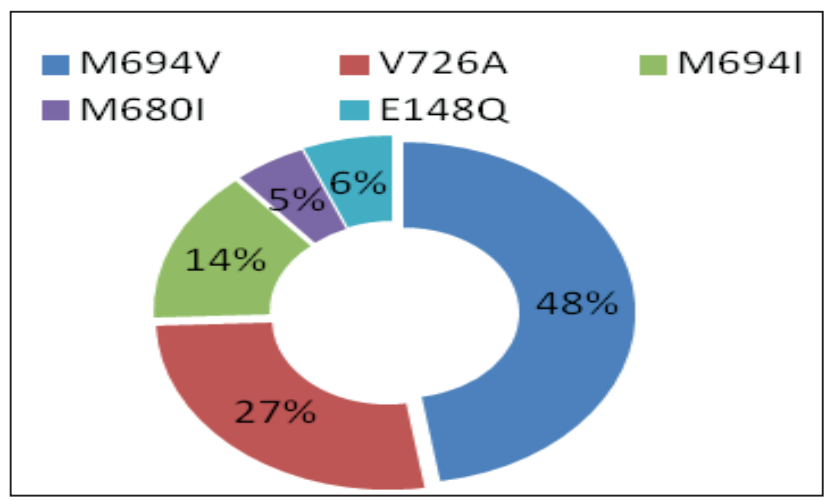

Figure 6. FMF in the Syrian population

mutations span only 12 mutations out of all gene mutations spectrum. Moreover, according to Jeru et al, heterozygosity might be coincidental in many patients due to the very high rate of mutations (25). Furthermore, other genes could be responsible for causing FMF (26, 27). Some authors suggested the hypothesis of having a dominant pattern of inheritance $(28,29)$. Epigenetics modulations as well as having hidden biomarkers might 


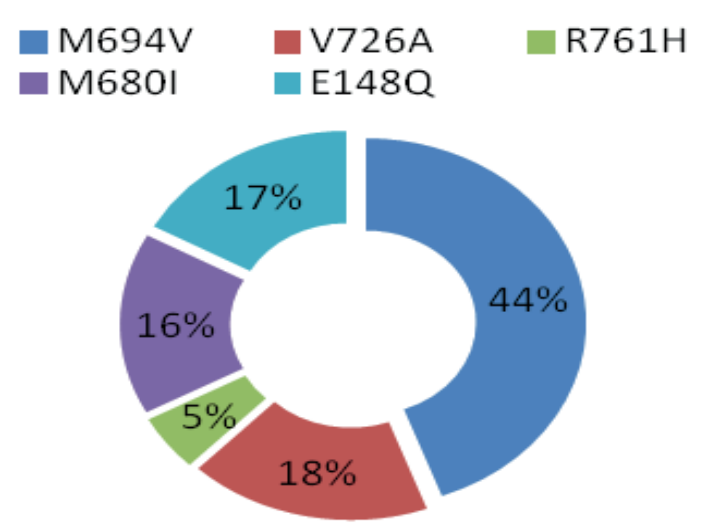

Figure 7. MEFVmutations in Iranian Azeri Turkish patients play a role in heterozygosity as a casualty of FMF in our cases.

\section{CONCLUSION}

Frequency of common mutations in our study show similar results in comparisons with Mediterranean countries like Egypt, Turkey, and Syria though the most common mutation in our study is M694V followed by E148Q.

\section{CONFLICT OF INTEREST: NONE DECLARED.}

\section{REFERENCES}

1. Gaven S. Oxford handbook of clinical immunology and allergy. 3rd ed. Oxford: Oxford University Press; 2013.

2. Touitou I. The spectrum of Familial Mediterranean Fever (FMF) mutations. Eur J Hum Genet. 2001; 9 (7): 473-483.

3. Wahadneh A, Habahbeh Z, et al. Genotype Analysis of Children with Familial Mediterranean fever at King Hussein Medical Center. JRMS J. 2010; 17: 80-83.

4. Balci B. MEFV gene mutations in familial Mediterranean fever phenotype II patients with renal amyloidosis in childhood: a retrospective clinicopathological and molecular study. Nephrology Dialysis Transplantation. 2002; 17(11): 1921-1923.

5. Mansour I, Delague V, Cazeneuve C, Dodé C, Chouery E, Pêcheux C et al. Familial Mediterranean fever in Lebanon: mutation spectrum, evidence for cases in Maronites, Greek orthodoxes, Greek catholics, Syriacs and Chiites and for an association between amyloidosis and M694V and M694I mutations. Eur J Hum Genet. 2001; 9(1): 51-55.

6. Kalkan G, Demirkaya E, Acikel C, Polat A, Peru H, Karaoglu A et al. Evaluation of the current disease severity scores in paediatric FMF: is it necessary to develop a new one?. Rheumatology. 2011; 51(4): 743-748.

7. Cazeneuve C, Ajrapetyan H, Papin S, Roudot-Thoraval F, Geneviève D, Mndjoyan E et al. Identification of MEFV-Independent Modifying Genetic Factors for Familial Mediterranean Fever. The American Journal of Human Genetics. 2000; 67(5): 1136-1143.

8. Somi M, Bonyadi M, et al. MEFV Common mutations detection in Iranian Azeri Turk patients with Ulcerative colitis: a case - control study. Life Science J. 2013; 10: 4.

9. Tomiyama N, Higashiuesato $\mathrm{Y}$, Oda T, et al. MEFV mutation analysis of familial Mediterranean fever in Japan. Clinical and Experimental Rheumatology. 2008; 26: 13-17.

10. Salah S, Hegazy R, Ammar R, Sheba H, AbdelRahman L. MEFV gene mutations and cardiac phenotype in children with familial Mediterranean fever: a cohort study. Pediatr Rheumatol. 2014; 12(1): 5.
11. Ivona A, Elon P, Luis G, et al. Familial Mediterranean Fever (FMF) in Moroccan Jews:Demonstration of a Founder Effect by Extended Haplotype Analysis. Am J Hum Genet. 1993; 53: 644-651.

12. Erten S, Erzurum C, Altunoglu A. Three Family Members with Familial Mediterranean Fever Carrying the M694V Mutation Showed Different Clinical Presentations. Intern Med. 2012; 51(13): 1765-1768.

13. Portincasa P, Scaccianoce G, Palasciano G. Familial mediterranean fever: a fascinating model of inherited auto inflammatory disorder. Eur J Clin Invest. 2013; 43(12): 1314-1327.

14. Gershoni-Baruch R, Shinawi M, Leah K, Badarnah K, Brik R. Familial Mediterranean fever: prevalence, penertrance and genetic drift. Eur J Hum Genet. 2001; 9(8): 634-637.

15. Bonyadi M, Esmaeili M, Karimi A, Dastgiri S. Common Mediterranean Fever Gene Mutations in the Azeri Turkish Population of Iran. Genetic Testing and Molecular Biomarkers. 2010; 14(1): 149-151.

16. Shinar Y, Kuchuk I, Menasherow S, Kolet M, Lidar M, Langevitz P. et al. Unique spectrum of MEFV mutations in Iranian Jewish FMF patients clinical and demographic significance. Rheumatology. 2007; 46(11): 1718-1722.

17. Oztuzcu S, Ulaşlı M, Ergun S, Iğci Y, Iğci M, Bayraktar R et al. Screening of common and novel familial mediterranean fever mutations in southeast part of Turkey. Molecular Biology Reports. 2014; 41(4): 2601-2607.

18. Solak M, Yıldız H, Köken R, Erdogan M, Eser B, Şen T et al. Analysis of Familial Mediterranean Fever Gene Mutations in 202 Patients with Familial Mediterranean Fever. Genetic Testing. 2008; 12(3): 341-344.

19. Medlej-Hashim M, Loiselet J, Lefranc G, and Mégarbané A. Familial Mediterranean Fever (FMF): from diagnosis to treatment. 2004; 14: 261-266.

20. Majeed H, El-Khateeb M, El-Shanti H, Abu Rabaiha Z, Tayeh M, Najib D. The Spectrum of Familial Mediterranean Fever Gene Mutations in Arabs: Report of a Large Series. Seminars in Arthritis and Rheumatism. 2005; 34(6): 813-818.

21. El Gezery D, Abou-Zeid A, Hashad D, El-Sayegh H. MEFV Gene Mutations in Egyptian Patients with Familial Mediterranean Fever. Genetic Testing and Molecular Biomarkers. 2010; 14(2): 263-268.

22. Medlej-Hashim M, Rawashdeh M, Chouery E, Mansour I, Delague V, Lefranc $G$ et al. Genetic screening of fourteen mutations in Jordanian familial Mediterranean fever patients. Human Mutation. 2000; 15 (4): 384-384.

23. Mattit H, Joma M, Al-Cheikh S, El-Khateeb M, Medlej-Hashim M, Salem $\mathrm{N}$ et al. Familial Mediterranean fever in the Syrian population: gene mutation frequencies, carrier rates and phenotype-genotype correlation. European Journal of Medical Genetics. 2006; 49(6): 481-486.

24. Bonyadi M, Esmaeili M, Jalali H, Somi M, Ghaffari A, Rafeey M et al. MEFV mutations in Iranian Azeri Turkish patients with familial Mediterranean fever. Clinical Genetics. 2009; 76(5): 477-480.

25. Jéru I, Hentgen V, Cochet E, Duquesnoy P, Le Borgne G, Grimprel E et al. The Risk of Familial Mediterranean Fever in MEFV Heterozygotes: A Statistical Approach. PLoS ONE. 2013; 8(7): e68431.

26. Dodé C, Pêcheux C, Cazeneuve C, Cattan D, Dervichian M, Goossens M et al. Mutations in the MEFV gene in a large series of patients with a clinical diagnosis of familial Mediterranean fever. American Journal of Medical Genetics. 2000; 92(4): 241-246.

27. Tchernitchko D, Moutereau S, Legendre M, Delahaye A, Cazeneuve C, Lacombe $C$ et al. MEFV analysis is of particularly weak diagnostic value for recurrent fevers in Western European Caucasian patients. Arthritis Rheum. 2005; 52(11): 3603-3605.

28. Booth D. The genetic basis of autosomal dominant familial Mediterranean fever. QJM. 2000; 93(4): 217-221.

29. Marek-Yagel D, Berkun Y, Padeh S, Abu A, Reznik-Wolf H, Livneh A. et al. Clinical disease among patients heterozygous for familial mediterranean fever. Arthritis Rheum. 2009; 60(6): 1862-1866. 